\title{
PERAN BMT GLOBAL MADANI INDONESIA DALAM PENANAMAN NILAI ENTREPRENEUR MAHASISWA ES (EKONOMI SYARIAH) INSTITUT KH.ADUL HALIM PACET MOJOKERTO
}

\author{
Muawanah \\ Institut Pesantren KH. Abdul Chalim Mojokerto \\ anadarto54@gmail.com
}

\begin{abstract}
Research with the title The Role of BMT Global Madani Indonesia In instilling entrepreneurial values of ES students (Islamic Economics) Institute of KH Abdul Chalim Pacet Mojokerto, BMT Global Madani Indonesia Pacet Mojokerto is present as a place for students to instill entrepreneurial values as well as intermediary institutions (fund collectors and channelers) in order to fulfill the commitment to participate in building small and medium classes of Indonesian Muslims, blessed by Allah SWT. This research uses the type of field research, so that this research is carried out intensively, in detail, and in depth on the object under study, because it is more broadly that the approach ultimately determines the results obtained.
\end{abstract}

Key Words: Global BMT Madani Indonesia, Entrepreneur Value

\begin{abstract}
ABSTRAK
Penelitian dengan judul Peran BMT Global Madani Indonesia Dalam penanaman nilai entrepreneur mahasiswa ES (Ekonomi Syariah) Institut KH Abdul Chalim Pacet Mojokerto, BMT Global Madani Indonesia Pacet Mojokerto hadir sebagai wadah mahasiswa dalam rangka menanamkan nilai entrepreneur sekaligus sebagai lembaga intermediary (penghimpun dan penyalur dana) dalam rangka memenuhi komitmen berpartisipasi membangun kelas kecil dan menengah muslim Indonesia yang diridhai Allah SWT. Penelitian yang dilakukan oleh peneliti kategori jenis penelitian lapangan, yaitu suatu penelitian yang harus dilaksanakan dengan intensif, terperinci, secara mendalam pada objek yang akan diteliti, bahwasanya pendekatan pada akhirnya akan menentukan dari hasil yang diperoleh.
\end{abstract}

Kata kunci: BMT Global Madani Indonesia, Nilai Entrepreneur

\section{PENDAHULUAN}

Pentingnya pengetahuan umum pada publik tentang menanamkan nilai-nilai entrepreneur dan khususnya mahaiswa di Institut K.H Abdul Halim Pacet Mojokerto. Ada beberapa alasan pokok yang publik harus mengetahuinya, sehingga penelitian ini penting untuk dilaksanakan. Pertama, lembaga keuangan syariah yang berada di Indonesia tidak terbatas pada Perbankan Syariah namun masih ada lembaga keuangan lainnya yaitu Lembaga Keuangan Mikro Syariah (LKMS) atau pada masyarakat luas terkenal dengan sebutan "Baitul Maal wa Tamwil" yang disingkat BMT. 
Kehahadirannya BMT sebagai sebuah wadah lembaga keuangan mikro syariah yang menjalankan kegiatan usahanya pada sektor nyata (rill) pada masyarakat kalangan menengah maupun kalangan bawah yang sejalan dengan kehadiran atau kelahiran Bank Mumalat Indonesia (BMI).

Kedua, "Baitul Maal wa Tamwil" yang (BMT) termasuk kategori lembaga (badan usaha) bidang keuangan yang berjenis lembaga (badan usaha) keuangan bukan atau non bank dan menjalankan operasinya atau bergerak dalam skala mikro seperti Koperasi Simpan Pinjam (KSP). Baitul Maal wa Tamwil” (BMT) adalah lembaga keuangan yang sesuai dengan ajaran Islam karena sesuai prinsip syariah serta memberikan nisbah dengan prinsip bagi hasil. Baitul Maal wa Tamwil" (BMT) bukan hanya menjalankan usaha dalam bentuk pengelolaan modal (uang) namun menjalankan operasinya pada kegiatan-kegiatan bidang sosial, antara lain: penyaluran dan mengumpulan dana zakat, menyalurkan serta mengumpulkan dana infaq dan shadaqah (ZIS). Berdasarkan namanya dapat dikategorikan bahwa Baitul Maal merupakan sebuah lembaga sosial sejenis BAZ (Badan Amil Zakat) sedangkan Baitut Tamwil berarti lembaga bisnis.

Ketiga, keberadaan Baitul Maal wa Tamwil” (BMT) mempunyai bermacammacam peran, yaitu: 1) Menghindari dan menjauhkan masyarakat pada kegiatan ekonomi yang melanggar ajaran Islam atau praktik non syariah. Caranya melaksanakan secara aktif kegiatan sosialisasi dikhalayak masyarakat akan pentingnya mengetahui dan melaksanakan sistem ekonomi Islam. 2) Pembinaan dan penyaluran dana usaha kecil dilakukan pada masyarakat . Caranya melakukan kegiatan pendampingan baik langsung maupun tidak langsung, melaksanakan pembinaan, memberikan penyuluhan, serta memberikan pengawasan terhadap kegiatanusaha yang dilakukan nasabah khususnya serta masyarakat pada umumnya. 3) Keterikatan maupun sifat mengantungkan pada rentenir harus segera dipisahkan dan dilepaskan, sebagian besar masyarkat mempunyai argumentasi yang utama memakai layanan rentenir yaitu terjadinya proses yang dilakukan saat traksaksi pinjam yang sangat praktis, simple dan cepat sehingga hanya memakan waktu sedikit dengan singkat atau tidak membutuhkan waktu lama. Oleh sebab itu kehadiran Baitul Maal wa Tamwil" (BMT) harus mampu mengimbangi rentenir dengan cara memberikan 
pelayanan pada masyarakat secara lebih cepat dan tanggap . 4) Pendistribusian dan rasa adil pada kegiatan ekonomi masyarakat dengan pendistribusian secara merata harus terjaga dengan baik. Contohnya apabila ada masyarakat yang melakukan pendanaan BMT harus mengetahui lebih teliti dalam mengelompokkan kategiri nasabah layak memperoleh pembiayaan dan nasabah tidak layak mendapatkannya. ${ }^{1}$ Dari penjelasan di atas tersebut membuktikan betapa perluanya menanamkan nilai entrepreneur pada masyarakat pada umumnya, khususnya mahasiswa di kampus IKHAC Pacet Mojokerto, sebagai langka masyarakat dalam peningkatan ekonomi melalui kegiatan entrepeneur sekaligus menanamkan kemandirian dalam menumbuh kembangkan kewirausahaan.

Jenis penelitian lapangan merupakan jenis penelitaian yang penulis gunakan. Penelitian lapangan yaitu penelitian yang dilaksanakan secara maksimal dengan terperinci, intensif serta pendalaman pada objek yang diteliti, karena akan menunjukkan secara panjang dan lebar bahwasannya pendekatan dan proses penelitian pada ujungnya akan menentukan pencapaian hasil yang diperoleh, sedangkan metodologi (process and procedure) juga mengacu pada penyesuaian dengan pendekatan yang akan digunakan oleh peneliti. ${ }^{2}$

Sumber penelitian kualitatif ini menggunakan data primer yaitu perkataan ( ucapan ) dan selanjutnya perilaku merupakan data skunder. ${ }^{3}$ Selanjutnya yang disebut jenis data primer dan data sekunder. Data primer yaitu data yang kita peroleh dari penelitian secara langsung dilapangan, melaksanakan observasi lapangan, dengan cara wawancara (interview) pada pihak yang berwenang. ${ }^{4}$ Menanyakan serta mengajukan beberapa pertanyaan untuk mendapatkan informasi sekaligus data-data maupun keterangan dan permasalahan pada saat penelitian melalui wawancara dengan pengurus BMT Global Madani Indonesia serta wawancara terhadap mahasiswa IKHAC Pacet Mojokerto. Data pendukung yang penulis manfaatkan dan gunakan disebut sebagai data sekunder yaitu data yang diperoleh dari arsip (dokumen) dan yang ada kaitannya

\footnotetext{
${ }^{1}$ Hendri Sudarsono, Bank dan Lembaga Keuangan Syariah (Yogyakarta: Andi Offset, 2003), 97.

2 Amin Abdullah, dkk., Metodologi Penelitian Agama (Yogyakarta: LP UIN Suka, 2006), 10.

${ }^{3}$ Lexy J. Moleong, Metode Penelitian Kualitatif (Bandung: PT. Remaja Rosdakarya, 2001), 112.

${ }^{4}$ Bambang Sunggono, Metodologi Penelitian Hukum (Jakarta: RajaGra nfo Persada, 2007), 37.
} 
dengan penelitian yang penulis teliti. Sedangkan pada teknik pengumpulan data peneliti menggunakan metode, dokumentasi, observasi, intervie (wawancara).

Metode dokumentasi adalah metode yang berasal dari bahan tertulis serta didapat dari penelitian di lapangan, pentingnya dokumentasi karena sangat berfaedah dalam penelitian, terdapat hal-hal penting yang dapat dimanfaatkan seperti peneliti menafsirkan, menguji, tidak kalah pentingnya dijadikan sebuah bukti untuk suatu pengujian $^{5}$. Dan metode dokumentasi juga digunakan supaya bermanfaat sebagai kelengkapan data yang didapatkan pada saat melakukan pengamatan, pengumpulan data yang berasal dari bukan manusia dapat berupa hasil catatan, buku-buku, transkrip, foto-foto, dan masih banyak yang lainnya.

Metode Observasi merupakan sebuah metode dipakai dengan melakukan pengamatan secara langsung maupun tidak langsung pada tindakan manusia atau objek penelitian ${ }^{6}$. Dalam arti sempit observasi adalah melakukan kegiatan mendengar dan mengamati tindakan manusia selama beberapa waktu, tanpa menyalah gunakan (manipulasi) serta melakukan pengendalian terhadap objek, menulis temuan-temuan yang membantu atau memenuhi syarat untuk dipakai pada tingkat penafsiran analisis. ${ }^{7}$

Metode Wawancara sering dikatakan sebagai metode interview adalah metode untuk memperoleh informasi secara lisan yang diperoleh peneliti dari responden adalah pengurus BMT Glogal Madani Indonesia sekaligus mahasiswa IKHAC Pacet Mojokerto dengan bertanya-tanya serta bertatap muka secara langsung ${ }^{8}$.

\section{TERMINOLOGI BAITUL MĀL WA AT-TAMWL (BMT)}

Kehadiran Baitul Mãl wat at-Tamwil (BMT) adalah sebagai wadah kegiatan ekonomi atau merupakan wadah keuangan syariah non perbankan termasuk kategori informal. Kategori informal artinya bahwa pendirianya dilakukan oleh kumpulan beberapa orang (swadaya masyarakat), tentunya tidak sama perbankan dan keuangan formal lainnya. ${ }^{9}$ BMT juga sebagai kegiatan ekonomi mikro. Peran penting yaitu memberikan kelancaran pada gerak roda kegiatan ekonomi bawah dengan terealisasi,

\footnotetext{
${ }^{5}$ Lexy J. Moleong, Metode Penelitian Kualitatif, 216-217.

${ }^{6}$ S. Margono, Metodologi Penelitian Pendidikan, (Jakarta: PT. Rineka Cipta, 1997), 158.

${ }^{7}$ Black James, Metode dan Masalah Penelitian Sosial, (Jakarta:Refika Aditama, 1999), 285

${ }^{8}$ Koenjtaraningrat, Metode- Metode Penelitian Masyarakat (Jakarta: Gramedia, 1994), 129.

${ }^{9}$ Andri Soemitra, Bank \& Lembaga Keuangan Syariah, (Jakarta: Kencana, 2009), 456.
} 
sebab sasaranya masuk kepada pengusaha kalangan bawah. Mempunyai nilai-nilai strategi serta teristimewa sebagai pendorong, pendobrak dan menggerakkan pembangunan untuk memberikan santunan pada kalanngan papa. ${ }^{10}$ Pembiayaan syariah yang dilaksanakan BMT kehadirannya dinantikan oleh para nasabah terutama nasabah berasal dari masyarakat ekonomi menengah sekaligus masyarakat ekonomi bawah, disebabkan hubungan atau mitra saling memberikan laba atau keuntungan kedua belah pihak yaitu nasabah dan pihak BMT, mempunyai kelebihan serta unggul karena termasuk lembaga keuangan yang tepat dan sangat sesuai untuk kerjasama dalam kemajuan UKM. Manajemen BMT (koperasi syariah) mempunyai fungsi utama yang ada dua, adalah fungsi menghimpun dana dan fungsi untuk pembiayaan yang dibutuhkan nasabah.

Fungsi funding (enghimpunan dana) BMT harus diplanning dan dilaksanakan dengan tepat dan sungguh-sungguh, agar masyarakat dapat tertarik, mempunyai daya miat tinggi, supaya terlibat langsung dengan pada BMT (koperasi syariah). Yang terpenting masyarakat dari program penghimpunan dana diberikan rasa percaya dan yakin pada BMT sebagai prinsip utamanya, maksudnya kepercayaan masyarakat banyak pada BMT (koperasi syariah) maka akan banyak pula masyarakat yang menabung, menyimpan, menitipkan dana pada BMT tersebut ${ }^{11}$

\section{PERAN BAITUL MĀL WA AT-TAMWIL (BMT)}

Pengertian peran yaitu peran adalah aspek dinamis tingkatan (kedudukan), Jikalau orang melakukan kewajiban dan menerima hak secara seimbang berdasarkan status atau tingkatannya, berati ia melaksanakan satu peran penting. Maka kesimpulan menunjukkan peran merupakan sebuah tindakan, perbuatan, ahlak yang diinginkan oleh semua manusia terhadap perorangan atau kelembagaan yang mempunyai status atau tingkatan pada level tertentu. Jika peran kita hubungkan dengan kelembagaan (BMT), peranlah yang mempunyai tanggungjawab maupun tugas sera wewenang dan wajib dilaksanakan pada kelembagaan (BMT). Menurut teori, peneliti menemukan empat (4) peranan BMT, antara lain: kesatu, Menjauhkan rakyat dari kegiatan

\footnotetext{
${ }^{10}$ Neni Sri Imaniyati, Aspek- Aspek Hukum BMT (Bandung: Citra Aditya Bakti, 2010), 3.

${ }^{11}$ Fitri Nurhayati dan Ika Saniyati Rahmaniyah, Koperasi Syariah (Surakarta: Era Adicitra Intermedia, 2012), 16.
} 
menyimpang (praktik ekonomi) yang melanggar agama karena sifat non Islam (menunjukan bahwa tindakan rentenir ataupun kelembagaan keuangan yang bersifat riba/ perbuatan haram). Ke-dua, melaksanakan kegiatan membina dan mendanai pada masyarakat yang mempunyai bisnis kecil sebab tidak sama dengan bank, BMT mengutamakan sekaligus intens pada UMKM. Ke-tiga, membebaskan rasa keterikatan yang dilakukan masyarakat untuk melakukan pembiayaan pada rentenir, BMT adalah kelembagaan keuangan mempunyai basis syariah sehingga memiliki kewajiban dan amanah BMT terpenting membuat masyarakat sadar sekaligus memberi penyelesaian atas masalah keuanngan kepada masyarakat, supaya dapat terhindar dari perbuatan tersesat, membelenggu, menjerat dari perbuatan rentenir ${ }^{12} \mathrm{Ke}$-empat, BMT harus selalu melindungi masyarakat terkait keadilan ekonomi dapat dilakukan dengan cara distribusi yang merata.

\section{ENTREPRENEUR}

Entrepreneur (wirausaha) yaitu seseorang yang dengan berani mengambil sebuah resiko untuk memdapatkan peluang kegiatan bisnis pada banyak waktu. Mempunyai keberanian dalam kegiatan bisnis yang mempunyai resiko artinya berani seorang diri dan tidak takut mengawali bisnis baru, tidak memiliki rasa cemas maupun rasa takut meskipun keadaan tidak mendukung, keadaan tidak pasti. Peluanglah yang sangat berguna bagi para entrepreneur dalam melaksanakan kegiatan bisnis new untuk mendapatkan kesempatan untung (profit) tinggi. Bukan sekedar kesempatan pada keadaan mengguntungkan (bagus), namun ketika kesempatan kurang baik (buruk) sekalipun. Seorang entrepreneur tidak kesulitan melakukan analisis akan permintaan barang atau jasa yang dibutuhkan masyarakat, meskipun keadaan kurang mendukung kegiatan bisnis seperti banjir bandang, hujan badai, tanah longsor, gempa bumi, gunung meletus, tsunami, angin topan dan kondisi kelangkaan terjadi di masyarakat . Entrepreneur (wirausaha) banyak mengeluti bisnis dapat menciptakan bisnis terbaru ataupun bisnis yang sudah lama dengan cara beli dari orang lain.

Dalam bukunya Suryana pendapat Thomas W Zimmerer, Entrepreneur (wirausaha) adalah terapan keinovasian, kreatifitas serta keberanian guna untuk

\footnotetext{
${ }^{12}$ Budi Widihartono, et al, Ekonomi dan Keuangan, 185.
} 
menyelesaiakan problematika serta mengupayakan pemanfaatkan kesempatan bisnis yang dijalani dalam kegiatan usahanya. Entrepreneur (wirausaha) sebuah perpaduan kegiatan dengan kreatif, inovasi dan pantang menyarah (sungguh-sungguh) ,berani pada resiko dihapani dengan keberanian, bekerja semaksimal mungkin serta usaha tekun,ulet untuk memperoleh dan meningkatkan bisnisnya. Sangat diperlukan semangat pada jiwa seorang pebisnis dengan kepercayaan tinggi dalam rangka membantu peningkatan dan perkembangan ekonomi negara . Terdapat macam- macam tulisan yang kita rasa cukup penting sehingga harus perhatian: a) Entrepreneur (wirausaha) dapat menjadikan kita paham dengat tepat, tentunya sebagaimana penting kita melakukan kegiatan bisnis, Selain itu juga dapat membantu individu, juga membantu untuk teman serta dapat memberi kesempatan atau peluang bekerja dan lapangan pekerjaan baru buat diri sendiri maupun orang lain dalam berbagai sektor. b) Membuka peluang para investor akan hal-hal baru (informasi) bisnis, mitra bisnis, dan seterusnya c) Dapat memperoleh pelatihan serta program-program yang dapat mendukung kegiatan bisnis secara rutin dan kontiniu serta berkesinambungan (penyuluhan,pembinaan) direrencanakan serta jelas dengan baik. ${ }^{13}$

Ciri-ciri (identifikasi) entrepreneur (wirausaha) antara lain: 1) Bertangggungjawab atas usaha yang dilakukannya harus dimiliki 2) Resiko yang moderat harus dipilih, yang berarti seorang wirausahawan harus terhindar dari resk baik yang kecil maupun besar. 3) Rasa percaya supaya memdapat keberhasilan harus melekat pada jiwa kewirausahaan 4) feedback dilaksanakan tanpa menunda. 5) Tanamkan strong (semangat) sekaligus kerja keras pada jiwa kewirausahaan dalam mencapai cita-cita demi kemajuan dan perkembangan pada waktu akan datang good (baik). 6) Memiliki perspektif serta berorientasi, juga berwawasan jauh kedepan. 7) Keterampilan organisasi SDM (sumber daya manusia) harus dimiliki guna tercipta nilai plus. 8) Mendahulukan dan mengahragai prestasi dari pada materi (uang). ${ }^{14}$ Disamping juga, seorang wirausaha harus dimiliki sifat-sifat yang bernilai positif yaitu : a) Rasa percaya pada diri sendiri b) Orientasi pada pekerjaan dan hasil. c) Berani ambil resk. d)

\footnotetext{
${ }^{13}$ Zulkarnain, Kewirausahaan, (Yogyakarta: Adicita Karya Nusa, 2006), 24-25.

14 Ibid., 25.
} 
Jiwa kepemimpinan. e) Menerapkan kedisiplinan. f) Orientasi pada masa yang akan datang.

\section{TUJUAN BMT GLOBAL MADANI INDONESIA PACET MOJOKERTO}

BMT Global Madani Indonesia Pacet Mojokerto hadir sebagai wadah mahasiswa dalam rangka menanamkan nilai entrepreneur sekaligus sebagai lembaga intermediary (penghimpun dan penyalur dana) dalam rangka memenuhi komitmen berpartisipasi membangun kelas kecil dan menengah muslim Indonesia yang diridhai Allah SWT.

BMT Global Madani Indonesia Pacet Mojokerto dalam rangka menawarkan keuntungan bagi anda berinvestasi secara syariah dengan aman, profitable, bebas dari unsur ribawi sekaligus turut berjuang meningkatkan posisi bargaining umat islam di Indonesia. Dengan berinvestasi di KJKS BMT Global Madani Indonesia Pacet Mojokerto, uang yang disimpan akan jauh berguna untuk pihak yang membutuhkan, menjadikan peningkatkan taraf hidup (sejahtera) pada ekonomi rakyatt dan mendapat berkah dengan nisbah bagi hasil lebih menjanjikan.

\section{AKTIVITAS BMT GLOBAL MADANI INDONESIA PACET MOJOKERTO}

BMT Global Madani Indonesia menawarkan sebuah simpanan dan berjarakk dengan sebutan simpanan Mudharabah merupakan sebuah kegiatan investasi berjangka yang menerapkan pada prinsip mudharabah mutlaqah (bagi hasil). Aktivitas yang dilakukan oleh KJKS BMT Global Madani Indonesia yaitu menghimpun dan menyalurkan dana secara maksimal (produktif) dalam bisnis (usaha) di sektor riil (nyata) maupun melakukan pendanaan pada rakyat kalangan bisnis tingkat bawah dan masyarakat kalangan usaha sedang dengan profesional tentunya mengacu ajaran dalam Islam yaitu prinsip syariah.

Aktivitas dan keuntungan yang diperoleh melalui BMT Global Mabani Indonesia antara lain:

- Pembiayaan untuk kesejahteraan usaha kecil dan menegah;

- Penghimpunan dana dalam berbagai bentuk simpanan, simpanan berjangka dan jasa layanan lainnya. 
a Penggunaan standar keamanan sistem brangkas disetiap kantor dan penjaminan dana dari mitra kerja KJKS BMT Global Madani Indonesia untuk memperkuat permodalan;

- Penerapan standar 5 C (character, capacity, capital dan condition) untuk menekan resiko terjadi kemacetan dan dana yang disalurkan tepat sasaran;

BMT Global Madani Indonesia Pacet Mojokerto juga menawarkan porsi bagi hasil atau tingkatan nisbah lebih untung seta kompeten.

Informasi Bagi Hasil Bulanan

\begin{tabular}{|c|c|c|}
\hline Waktu & Nasabah & BMT Global Madani \\
\hline Tri wulan / 3 bulan & $29 \%$ & $71 \%$ \\
\hline Semester /6 bulan & $30 \%$ & $70 \%$ \\
\hline 1 tahun /12 bulan & $33 \%$ & $67 \%$ \\
\hline
\end{tabular}

Ketentuan Simpanan Mudharabah antara lain:

$>$ Membutuhkan masa Ijabah jangkanya minimum enam bulan.

$>$ Diberikan nisbah (bagi hasil) cash, ditranfekanr ke rekening Bank yang berbeda atau memindah bukukan pada rekening simpanan di BMT Global Madani Indonesia, atau titip diakumulasi sehingga dapat mengambil waktu jatuh tempo.

$>$ Secara otomatis diperpanjang

$>$ Satu juta Rupiah (Rp.1.000.000,00) minimal setoran awal atau kelipatannya untuk nominal investasinya

\section{Ilustrasi Perhitungan Bagi Hasil Simpanan Berjangka BMT Global Madani Pacet Mojokerto}

Simpanan Mudharabah pada bulan april 2019 sebesar Rp 10.000.000 dengan jangka waktu satu tahun dilakukan oleh Ibu Fatimah dalam bentuk investasi

Kesepakatan antara Bu Fatimah dengan BMT Global Madani Indonesia Pacet Mojokerto nisbah bagi hasilnya yaitu 33\% untuk Bu Fatimah dan 67 \% untuk BMT Global Madani Indonesia Pacet Mojokerto. 
Simpanan Mudharabah dari para anggota BMT Global Madani Indonesia Pacet Mojokerto saldo rata-ratanya pada bulan tersebut adalah 500.000.000

BMT Global Madani Indonesia pacet Mojokerto memperoleh pendapatan yang dibagi hasilkan kepada nasabah (anggota ) sejumlah Rp 17.500.000

Bagi hasil yang diperoleh Bu Fatimah adalah

Rp $\quad 10.000 .000$

$$
\text { X Rp 17.500.000 X 33\%= Rp } 115.500
$$

Rp 500.000.000

Pemberian Bagi hasil dilakukan setiap bulan atau dapat diakumulasi sehingga dalam setahun (akhir kontrak) perkiraan bagi hasil yang diterima Bu Fatimah sebagai berikut :

$\mathrm{Rp} 115.500 \times 12=\mathrm{Rp} 1.386 .000$

\section{PERBANDINGAN INVESTASI}

\begin{tabular}{|c|c|c|}
\hline Keterangan & $\begin{array}{l}\text { Bank Konvensional } \\
\text { (Deposito) }\end{array}$ & $\begin{array}{c}\text { BMT Global Madani } \\
\text { (Investasi / Simpanan Berjangka } \\
\text { Mudharabah ) }\end{array}$ \\
\hline Masa & $\begin{array}{l}\text { Enam bulan, satu tahun, } \\
\text { Otomatis perpanjangan } \\
\text { (Automatic Roll Over) }\end{array}$ & $\begin{array}{l}6 \text { bln, } 1 \text { thn, } \\
\text { otomatis perpanjangan } \\
\text { (Automatic Roll Over) }\end{array}$ \\
\hline Nisbah & $\begin{array}{c}\text { Memperoleh bunga tetap (Flat) } \\
\text { dari investasinya }\end{array}$ & $\begin{array}{l}\text { Memperoleh Bagi Hasil yang } \\
\text { besarnya proposional disesuaikan } \\
\text { dengan hasil usaha perusahaan }\end{array}$ \\
\hline $\begin{array}{c}\text { Penarikan } \\
\text { Sebelum Jatuh } \\
\text { Tempo }\end{array}$ & $\begin{array}{l}\text { Ada penalti bagi nasabah serta } \\
\text { diakui sebagai keuntungan Bank }\end{array}$ & $\begin{array}{l}\text { pengingkaran akad (dikenakan } \\
\text { infaq) untuk digunakan murni } \\
\text { kegiatan sosial keagamaan serta } \\
\text { tidak diakui sebagai keuntungan } \\
\text { BMT }\end{array}$ \\
\hline
\end{tabular}


FASILITAS BMT GLOBAL MADANI INDONESIA PACET MOJOKERTO

Penawarkan banyak fasilitas dari BMT Global Madani Indonesia Pacet Mojokerto antara lain: pelayanan jemput bola diterapkan oleh BMT Global Madani Indonesia, dengan cara petugas dari BMT Global Madani Indonesia yang akan datang menemui nasabah atau customer. BMT Global Madani Indonesia Pacet Mojokerto memiliki dan bekerja sama dengan bank koresponden sehingga apabila nasabah ingin melakukan traksaksi cukup dengan melakukan transfer (Bank BRI Syariah atas nama Sirojudin And Mujtaba Mitra Zuana).

\section{KESIMPULAN}

Hadirnya BMT Global Madani Indonesia Pacet Mojokerto Surya di tengahtengah kampus Institut KH. Addul Chalim Pacet Mojokerto, khususnya bagi mahasiswa ES (Ekonomi syariah) dapat dijadikan wadah dalam rangka menanamkan nilai entrepreneur sekaligus sebagai lembaga intermediary (penghimpun dan penyalur dana)dan masyarakat, sedangkan bagi masyarakat sekitar dapat berinvestasi sekaligus memperoleh keuntungan berinvestasi secara syariah dengan aman, profitable, bebas dari unsur ribawi sekaligus turut berjuang meningkatkan posisi bargaining umat islam di Indonesia.

Investasi pada BMT Global Madani Indonesia Pacet Mojokerto uangnya sanagt berguna pada orang yang membutuhkan, peningkatan kelayakan hidup (sejahtera), ekonomi rakyat, mendapat berkah bagi hasil tentunya mmendapatkan keuntungan, dapat juga membantu meringankan beban dan meningkatkan taraf hidup masyarakat. Khususnya juga mahasiswa dari berbagai layanan jasa keuangan yang tersedia.

\section{DAFTAR PUSTAKA}

Abdullah, Amin, dkk., Metodologi Penelitian Agama, Yogyakarta: LP UIN Suka, 2006.

Koenjtaraningrat, Metode-Metode Penelitian Masyarakat (Jakarta: Gramedia, 1994).

Nurhayati Fitri, Ika Saniyati Rahmaniyah, Koperasi Syariah (Surakarta: Era Adicitra Intermedia, 2012). 
Soemitra Andri, Bank \& Lembaga Keuangan Syariah (Jakarta: Kencana, 2009)

Sudarsono Hendri, Bank dan Lembaga Keuangan Syariah (Yogyakarta: Andi Offset, 2003

Sunggono Bamabang, Metodologi Penelitian Hukum (Jakarta: RajaGra nfo Persada, 2007)

Sri Imaniyati Neni, Aspek-Aspek Hukum BMT (Bandung : Citra Aditya Bakti, 2010

Margono S, Metodologi Penelitian Pendidikan (Jakarta: PT. Rineka Cipta, 1997),

Moleong, Lexy J., Metode Penelitian Kualitatif Bandung: PT. Remaja Rosdakarya, 2001.

James Black, Metode dan Masalah Penelitian Sosial (Jakarta:Refika Aditama, 1999

Budi Widihartono, et al, Ekonomi dan Keuangan.

Zulkarnaen, Kewirausahaan, Yogyakarta: Adi Cita Karya Nusa, 2006. 